\title{
Editorial
}

\section{Organic Electronics}

\author{
K. N. Narayanan Unni, ${ }^{1}$ Himadri S. Majumdar, ${ }^{2}$ and Manoj A. G. Nambuthiry ${ }^{3}$ \\ ${ }^{1}$ CSIR-National Institute for Interdisciplinary Sciences and Technology, Thiruvananthapuram 695 019, India \\ ${ }^{2}$ VTT Technical Research Centre of Finland, Micronova, Tietotie 3, 02150 Espoo, Finland \\ ${ }^{3}$ Indian Institute of Science Education and Research, Thiruvananthapuram 695 016, India \\ Correspondence should be addressed to K. N. Narayanan Unni; unni@niist.res.in
}

Received 19 September 2013; Accepted 19 September 2013

Copyright (C) 2013 K. N. Narayanan Unni et al. This is an open access article distributed under the Creative Commons Attribution License, which permits unrestricted use, distribution, and reproduction in any medium, provided the original work is properly cited.

Although the class of compounds called organic semiconductors was known from early 20th century, it is with the invention of organic light emitting diode (OLED) by Tang and Vanslyke in 1987, the new research area-organic electronics-began flourishing. With the progress made in synthetic techniques, purification processes, and fabrication technologies, OLEDs have matured into commercial applications. It is seen that organic photovoltaic (OPV) cells and organic thin film transistors (OTFT) are also following suite. Both polymers and small molecules have been widely studied for possible use in OLEDs, OPV, and OTFT. The prospect of developing flexible and printable electronics on large area makes this field further attractive.

This special issue on Organic Electronics contains 5 research articles which cover organic solar cells, organic light emitting diodes, and back-plane technology for OLED based displays.

Though tandem device structure could be employed to increase the open circuit voltage in organic solar cells, in certain cases this results in charge trapping at the interface and reduced filling factor. W. Nie et al. address this issue by doping the interconnect layer $(\mathrm{ZnO})$ with $\mathrm{Ag}$ nanoparticles which results in the mitigation of trapping effect.

In another article, dependence of performance on solution concentration of inverted organic solar cells based on eosin-Y-Coated $\mathrm{ZnO}$ nanorod arrays and MEHPPV and PCBM solutions have been studied by R. T. Ginting et al.

R. Rahimi et al. have systematically studied the optical constants, morphology, and structure of thin films of an important perylene derivative, PTCDI-C8, which will be useful for device design and optimization.

Enhanced charge carrier transport, optimized exciton distribution, and better harvesting of triplets excitons have been obtained by a mixed interlayer in a fluorescent bluephosphorescent yellow-white OLED by C.-H. Gao et al. A reasonably high efficiency of 29 lumens/watt underlines the importance of this device structure.

The variations in the threshold voltages of driving TFT and the OLED give rise to nonuniform colors in an OLED display. One way of addressing this issue is to deploy more TFTs as part of compensating circuits. The compensation circuit, proposed by C.-L. Fan et al., promises excellent control over the variation in the threshold voltages of TFT and OLED. The circuit contains 5 TFTs and one capacitor. Any improvement in this area with low temperature polycrystalline silicon (LTPS) is important as these problems aggravate as we go to larger and larger displays.

We do believe that these articles not only enrich our knowledge about organic semiconductor devices but also indicate the existence of a lot more technological issues which make the field organic electronics all the more attractive and challenging.

K. N. Narayanan Unni Himadri S. Majumdar Manoj A. G. Nambuthiry 

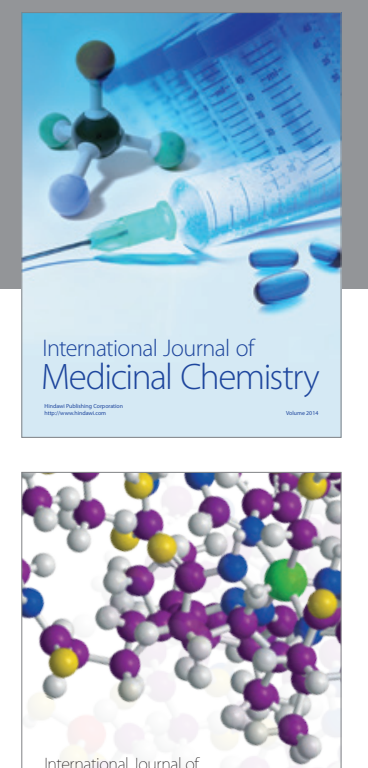

\section{Carbohydrate} Chemistry

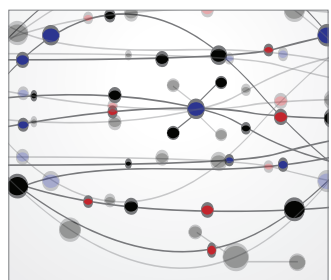

The Scientific World Journal
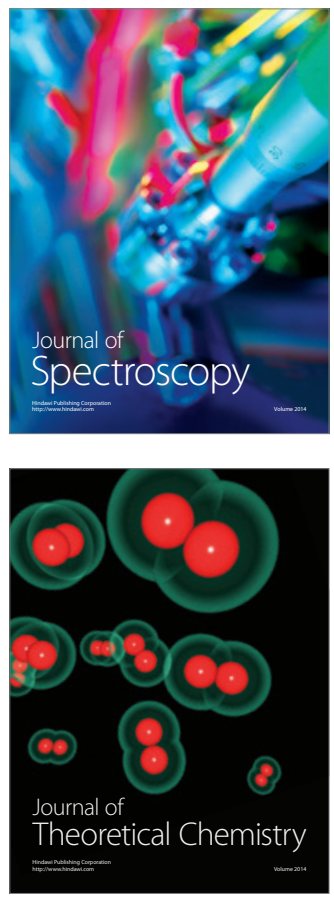
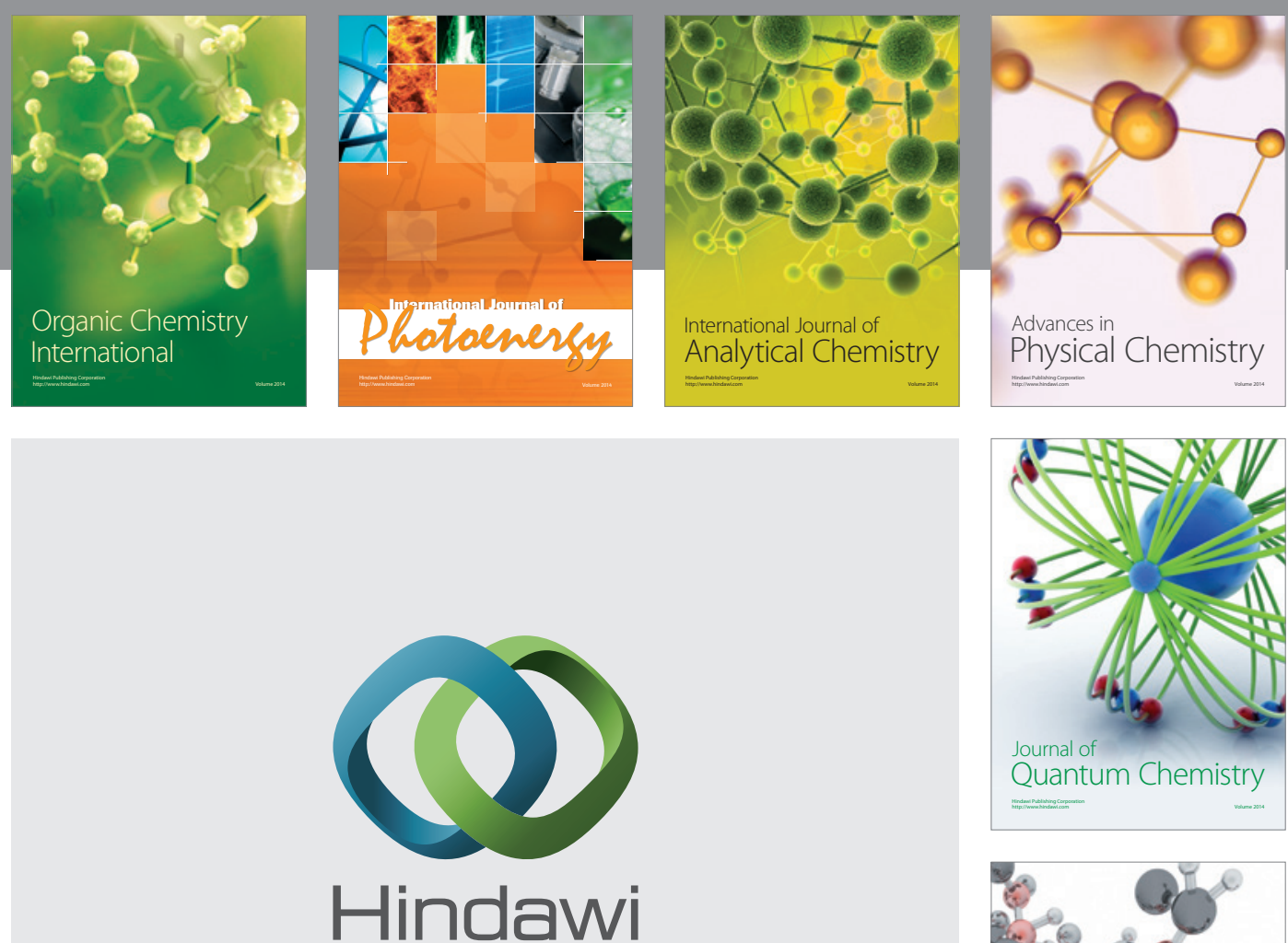

Submit your manuscripts at

http://www.hindawi.com

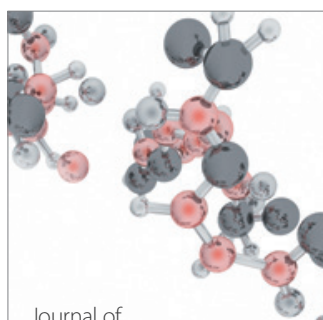

Analytical Methods

in Chemistry

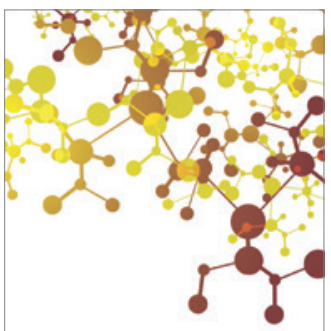

Journal of

Applied Chemistry

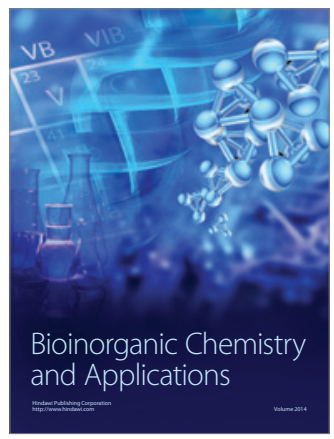

Inorganic Chemistry
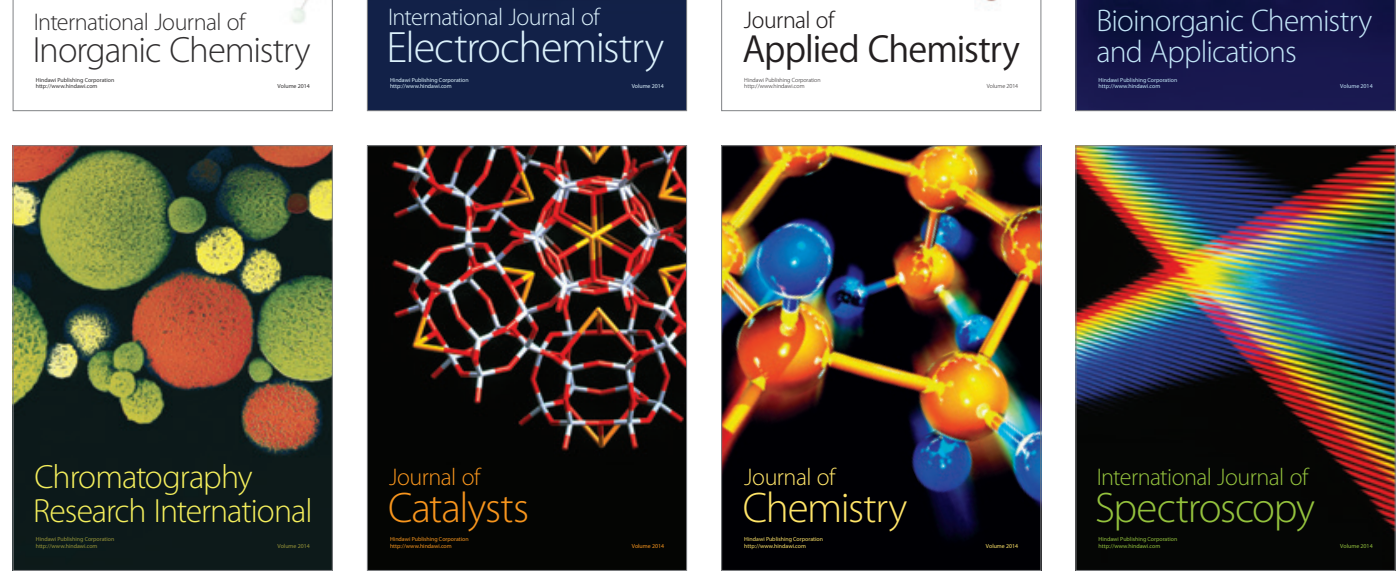